\title{
Partial vision recovery after iatrogenic retinal artery occlusion
}

\author{
Shu-Fang Hsiao and Yi-Hsun Huang*
}

\begin{abstract}
Background: To describe the first case of partial vision recovery in a 32-year-old woman with iatrogenic retinal artery occlusion (RAO) following glabella calcium hydroxylapatite (CaHA) injection, and to explore appropriate diagnostic and therapeutic measures according to a literature review.

Case presentation: A 32-year-old woman had left eye RAO and a bilateral visual field defect after CaHA injection into the glabella region. Topical and systemic intraocular pressure lowering agents, isovolemic hemodilution, globe massage, and anticoagulation with acetylsalicylic acid were prescribed. Carbogen inhalation and oral corticosteroids were also given. In addition to the above therapies, hyperbaric oxygen therapy (HBOT) was implemented as adjuvant treatment. The final best corrected visual acuity (BCVA) of the left eye improved from hand motion at $15 \mathrm{~cm}$ to 0.1 . Improved retinal circulation and decreased retinal vessel leakage were found in the follow-up fluorescein angiography. However, there were still multiple emboli in the conjunctival and retinal arteries.

Conclusion: This is the first case report on partial recovery of BCVA after iatrogenic RAO following cosmetic CaHA injection. Because no reliable treatments have been reported for such complications, HBOT may be considered as an alternative adjuvant therapy.
\end{abstract}

\section{Background}

As soft-tissue augmentation of the face has become more common, there has been an increasing number of cases of ocular complications after facial filler injections, including hypersensitivity reactions, ecchymosis, anterior chamber inflammation, strabismus, ptosis, ophthalmoplegia, and retinal vessel occlusion [1]. Among these complications, permanent visual loss due to retinal artery occlusion (RAO) is the most devastating. To date, there have been no definite therapeutic guidelines developed for iatrogenic RAO. Although a few cases with vision improvement were reported in the past, [2-4] none of these cases were related to RAO following calcium hydroxylapatite (CaHA, RADIESSE ${ }^{\circ}$ ) injection. We herein describe a case of iatrogenic RAO following CaHA filler injection with vision and retinal circulation improvement after treatment. We used hyperbaric oxygen therapy (HBOT) as adjuvant treatment in this patient. To the best of our knowledge, this is the first case report of partial vision recovery in RAO following

\footnotetext{
*Correspondence: jackhyh@gmail.com
Department of Ophthalmology, National Cheng Kung University Hospital,

* Correspondence: jackhyh@gmail.com
Department of Ophthalmology, National Cheng Kung University Hospital, College of Medicine, National Cheng Kung University, 138 Sheng Li Rd, Tainan, Taiwan
}

CaHA filler injection. We also provide a literature review to discuss the issues of diagnosis and treatment of this vision threatening disorder.

\section{Case presentation}

A 32-year-old woman sought treatment in the emergency department reporting sudden vision loss in her left eye. Four hours previously, she received vaginal plastic surgery and CaHA filler injection into the glabella region by a local plastic surgeon under general anesthesia. After waking up, she noted vision loss in her left eye, and was immediately transferred to our hospital. The initial best-corrected visual acuity (BCVA) at our emergency department was hand motion at $15 \mathrm{~cm}$ in the left eye and 1.0 in the right. The left pupil was dilated with a positive relative afferent papillary defect. There was neither ophthalmoplegia nor strabismus. Slit lamp examination showed multiple emboli along the conjunctival vessels (Figure 1). Fundoscopy in the right eye $(\mathrm{OD})$ revealed normal findings (Figure 2A), while the left eye (OS) showed multiple emboli in the whole choroidal layer (Figure 2B). The corresponding spectral-domain OCT showed normal choroidal vascularity in the right eye (Figure $2 \mathrm{C}$ ). In the left eye, multiple 


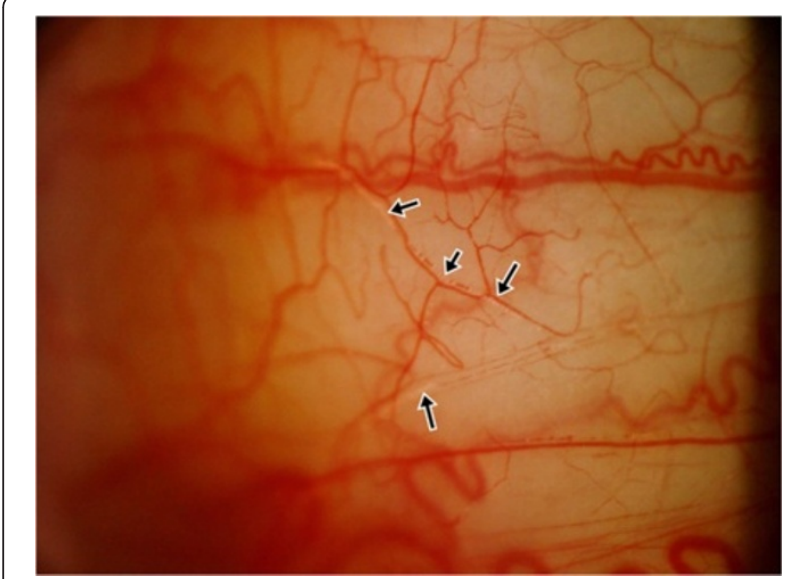

Figure 1 Multiple emboli along the conjunctival vessels.

hyper-reflective depositions, which resulted in dark acoustic shadows (arrow head) in the retinal layer, were found (Figure 2D). Close-up imaging revealed distal RAOs (Figure 2E). Magnetic resonance imaging (MRI) showed no evidence of acute brain infarction, however, there were high-attenuation materials around the glabella region, which were compatible with the CaHA filler injections (Figure 3). Fundus fluorescein angiography (FAG) obtained on the second hospital day showed multiple absences of retinal perfusion in the arteriovenous phase
(Figure 4A), and fluorescein leaking out of the occlusive retinal artery was found in the late phase (Figure 4B). Under the diagnosis of iatrogenic RAO, the therapies were administered to shorten the ischemic period on the basis of the European Assessment Group for Lysis in the Eye (EAGLE) guidelines, [5] including topical and systemic intraocular pressure lowering agents, isovolemic hemodilution, globe massage, and anticoagulation with acetylsalicylic acid. In addition, carbogen inhalation and oral corticosteroids were also provided.

Despite the treatment, progressive blurred vision was still found in the following few hours. Intra-arterial fibrinolysis using recombinant tissue plasminogen activator was not performed because of higher rates of adverse side effects [5]. An alternative treatment option, HBOT, was performed. Our patient received $100 \%$ oxygen via a face mask at a maximum ambient pressure of 2.5 atmospheres absolute. The protocol for the treatment was 10 minutes of compression, followed by a hyperbaric phase of 60 minutes, and 15 minutes of decompression. The treatment schedule was HBOT 3 times within the initial 24 hours, and 3 more treatments within the following 72 hours, for a total of 6 treatments. Conjunctival biopsy (OS) was performed later, which revealed multiple calcified foreign bodies in the vessel lumens (Figure 5). The visual acuity remained stable after the treatments, and the patient was discharged. Three months after onset, the BCVA improved from hand

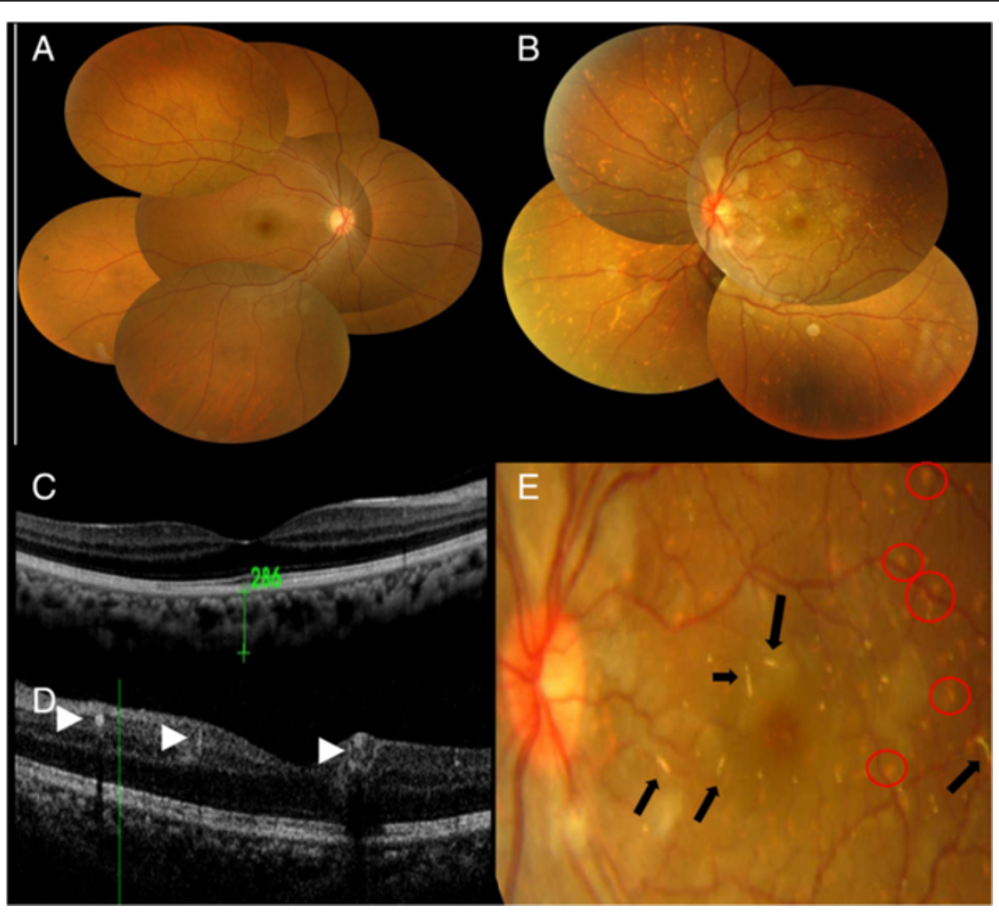

Figure 2 Fundus picture. (A) Normal in the right eye. (B) There were multiple emboli in the whole choroidal layer. (C) The corresponding SD-OCT in the right eye showed normal choroidal vascularity. (D) In the left eye, multiple hyper-reflective depositions (arrow head) were found in the retinal layer, which caused dark acoustic shadows, indicating CaHA emboli. (E) Magnification of the macular region shows multiple emboli (arrow) obstructing the distal retinal artery and choroidal layer (circle). 


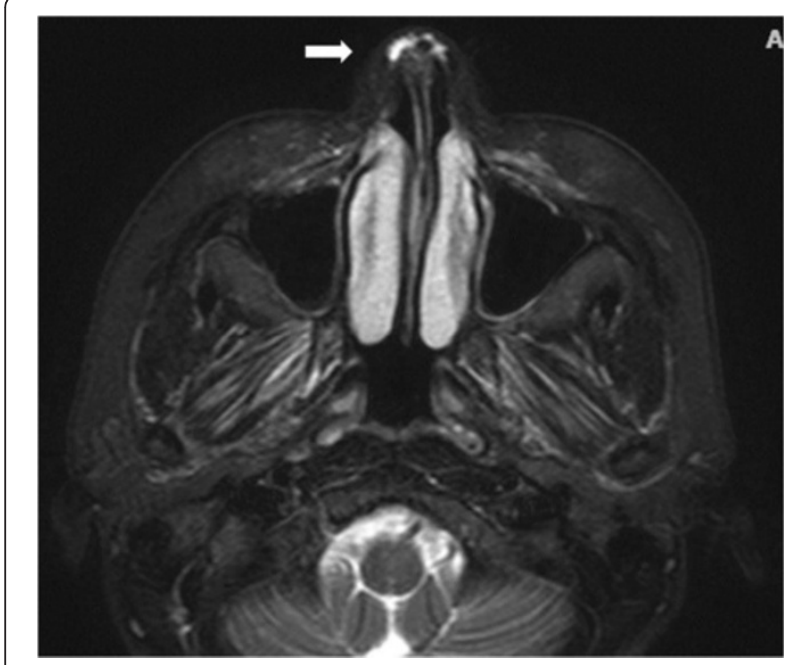

Figure 3 T2W1MRI demonstrated high-attenuation material around the glabella region (arrow), corresponding with $\mathrm{CaHA}$ filler.

motion at $15 \mathrm{~cm}$ to 0.1 (OD). Fundoscopy in the left eye still showed multiple emboli in retinal vessels (Figure 6). Follow-up fluorescein angiography (FAG) showed improved retinal circulation (Figure $4 \mathrm{C}$ ) and decreased retinal vessel leakage (Figure 4D).

\section{Discussion}

Our literature review revealed that a retrograde embolic mechanism is generally thought to be the pathogenesis

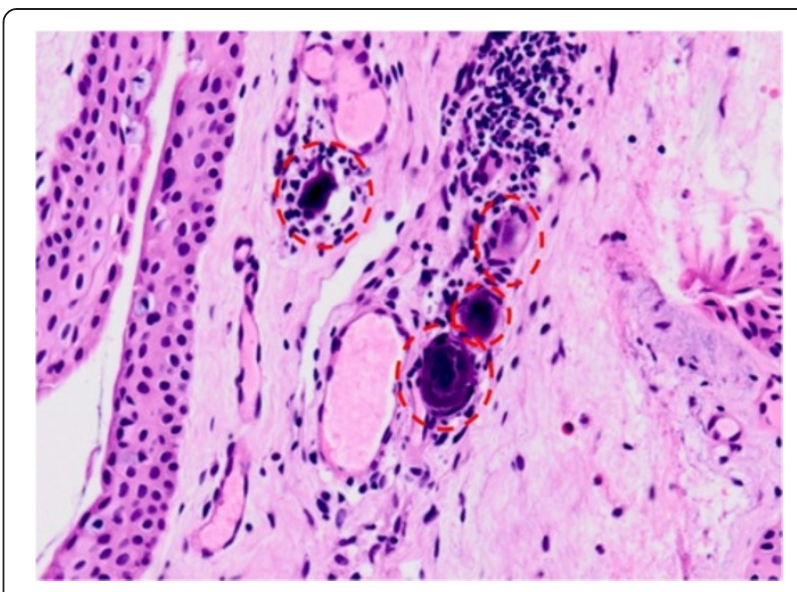

Figure 5 The pathology of a conjunctival biopsy showed several calcified materials (dashed circle) in the capillary lumen. Normal calcifications are not likely and foreign bodies are more likely to be present.

of RAO after cosmetic facial filler injections $[4,6]$. Once an injection pressure is higher than the systolic arterial pressure, the injected material displaces the arterial blood and travels proximally past the origin of the retinal artery [7]. When the plunger is released, the arterial systolic pressure then propels the resulting column of material into the ophthalmic artery and its branches [6]. We searched PubMed and MEDLINE (1950 through February 2014) using the key words "visual loss", "visual impairment", "blindness", "retinal artery occlusion", "facial fillers", "facial
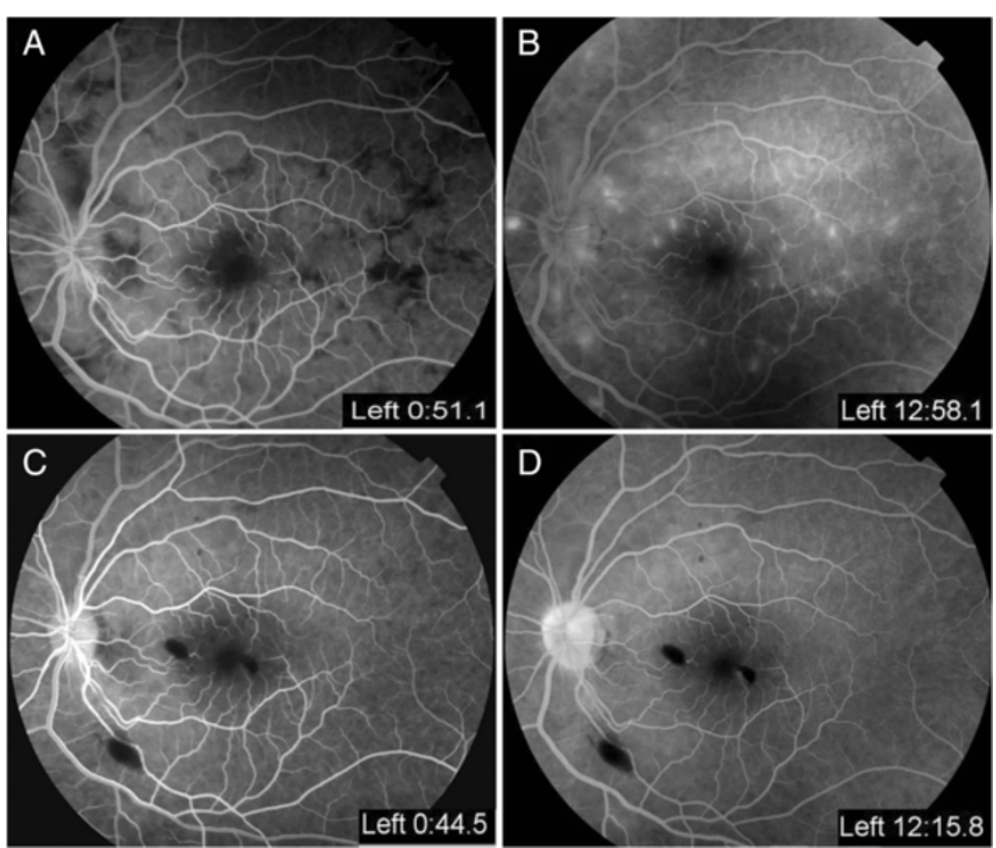

Figure 4 Fundus fluorescein angiography (FAG) obtained on the second hospital day. (A) Multiple absences of retinal perfusion in the arteriovenous phase. (B) Fluorescein leaking out of the occlusive retinal artery was found in the late phase. (C) FAG obtained 5 weeks later revealed recovery of retinal circulation, and (D) decrease retinal vessel leakage. 


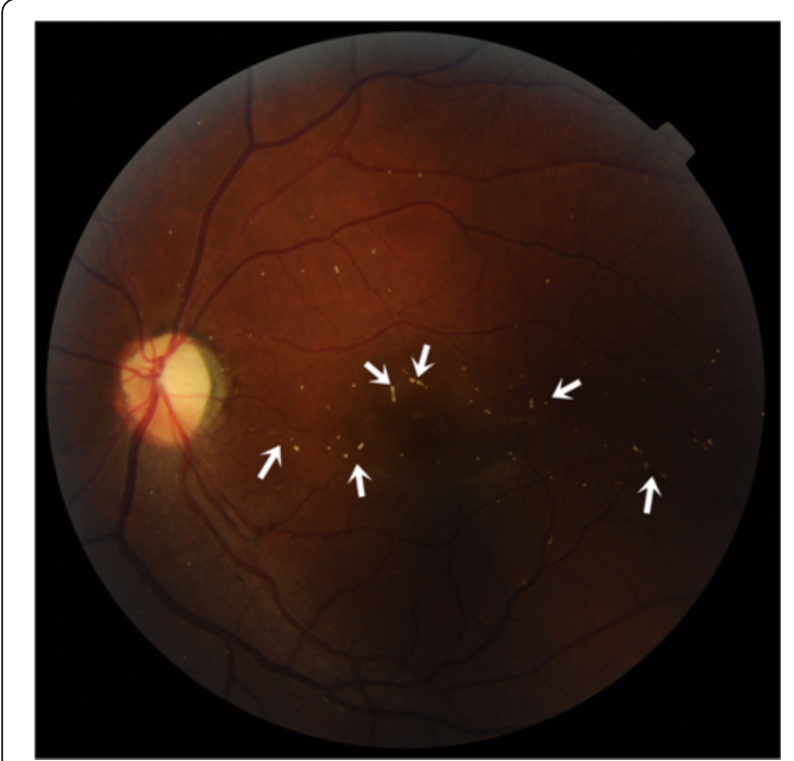

Figure 6 Three months after treatment, the fundoscopic image of the left eye still showed multiple emboli in retinal vessels (arrow).

injections", and "cosmetic procedure". Forty-six case reports of visual disturbance following facial filler injections were identified through the first screening [2-4,6,8-30]. We excluded the cases of visual disturbance not due to retinal artery occlusion after cosmetic injections. Only 2 cases met our criteria, which were related to CaHA filler injection [2,9]. We summarized these 2 cases and made a comparison with our patient (Table 1).

Our case is the first case report of vision and circulation improvement in posterior segment ischemia due to CaHA filler injections. A variety of measures have been advocated in an attempt to treat non-arteritic retinal artery obstruction, but there were no generally agreed upon treatment regimens, with no suggested treatment regimens for iatrogenic RAO. In 2010, Sung et al. [2] first reported a case of anterior segment ischemia concurrent with vascular embolization after injection of CaHA. The main affected part was the anterior segment, and the involved vessel was the long posterior ciliary artery. Therapies included a topical antibiotic, topical steroids, and low-dose oral corticosteroids. The significant improvement in final visual acuity was determined by the resolution of corneal edema and severe anterior chamber inflammation, rather than an improvement in the posterior choroidal circulation. Theoretically, a limited nasal choroidal ischemia, sparing the macula, will not result in an obvious visual acuity disturbance. Kim and Chou reported a patient with bilateral blindness after CaHA injection in 2013 [9]. The main affected part was the posterior segment, and the involved vessel was the ophthalmic artery. However, only limited information on the treatments was provided, and the final visual outcome was no light perception in both eyes. In our case, the injured arteries were the retinal artery and short posterior ciliary artery. We provided the treatment immediately when the diagnosis was made. We completed 5 steps of a 6-step therapy, which followed the EAGLE study, [5] including topical and systemic lowering of intraocular pressure agents, ocular massage, hemodilution, and antiplatelet therapy with acetylsalicylic acid. In addition, interventions that had been used as treatments for acute retinal artery occlusion were provided at the same time, including carbogen breathing, and low dose oral prednisolone. Intra-arterial fibrinolysis using recombinant tissue plasminogen activator was not performed; instead, HBOT was implemented in 6 treatments. Three months later, the BCVA in the left eye increased from $\mathrm{HM} / 15 \mathrm{~cm}$ to 0.1 , and the follow-up FAG indicated recovery of retinal perfusion.

In our literature review of 46 case reports, 15 reported therapies for iatrogenic RAO, including dilation of the artery by breathing carbon dioxide/carbogen [20] and using an oral vasodilator, $[19,29]$ physical removal of the obstruction by ocular massage, $[4,20,26,27,29]$ reduction of intraocular pressure by anterior chamber paracentesis, [4,27] intravenous acetazolamide or mannitol, $[3,4,10,27,29]$ intraarterial thrombolysis, [4,22] anti-platelet therapy, [10,12,19] reduced red blood cell rigidity by hemodilution, [20] and systemic steroids to reduce retinal edema [2,11,12,21-24]. Only 4 of the 47 cases, including our case, showed improvements in visual acuity [2-4]. The number of cases was too small to provide a safe, convincing, and reliable treatment protocol for RAO. In our case, we observed a shorter occlusion time and faster restoration of perfusion. Thus, the rational goal of treatment should be shortening the occlusion time and increasing perfusion.

The major difference in our case from previous reports is the early HBOT within 24 hours after the onset of symptoms. A number of investigations have shown that early HBOT within 24 hours after the onset of symptoms had beneficial effects for visual acuity improvements in eyes with RAO, and there were no serious major complications [31-34]. However, for iatrogenic RAO, there have been no case reports or large clinical trials to prove the efficacy of HBOT. Breathing 100\% oxygen under 2.5 atmospheres absolute can increase dissolved plasma oxygen by almost 17-fold than breathing room air. Under such hyperbaric conditions, enough dissolved plasma oxygen can meet the normal requirements of the body at rest without the need for hemoglobin [35]. Therefore, more oxygen can be delivered deeper into the ocular tissue, including the inner retina via diffusion, to support tissue survival until recovery of perfusion in patients with iatrogenic RAO [34]. Thus, though the CaHA particles still remained in place for a few months after occlusion, we surmised that the effect of HBOT in iatrogenic RAO could be the increase in oxygen perfusion into the retina, which further contributed to the improvement in visual acuity. 
Table 1 Characteristics and clinical data of 3 patients with CaHA filler injection

\begin{tabular}{|c|c|c|c|c|c|c|c|c|c|c|c|c|c|}
\hline \multirow[t]{2}{*}{ Case } & \multirow{2}{*}{$\begin{array}{l}\text { Age } \\
\text { (yr) }\end{array}$} & \multirow{2}{*}{ Sex } & \multirow[t]{2}{*}{ Eye } & \multirow{2}{*}{$\begin{array}{l}\text { Injection } \\
\text { site }\end{array}$} & \multirow[t]{2}{*}{ Diagnosis } & \multirow{2}{*}{$\begin{array}{l}\text { Associated ocular } \\
\text { symptoms }\end{array}$} & \multirow{2}{*}{$\begin{array}{l}\text { Visit/Therapy } \\
\text { interval }\end{array}$} & \multicolumn{2}{|c|}{ Treatment } & \multirow[t]{2}{*}{ Initial BCVA } & \multicolumn{2}{|r|}{ Outcome } & \multirow[t]{2}{*}{ Follow - up } \\
\hline & & & & & & & & $\begin{array}{l}\text { EAGLE 6-step } \\
\text { therapy }\end{array}$ & $\begin{array}{c}\text { Adjunctive } \\
\text { treatment }\end{array}$ & & $\begin{array}{l}\text { Final } \\
\text { BCVA }\end{array}$ & $\begin{array}{l}\text { Other ocular } \\
\text { symptoms }\end{array}$ & \\
\hline $\begin{array}{l}\text { Sung } \\
\text { MS, } \\
2010 \text { [2] }\end{array}$ & 25 & M & Right & glabella & $\begin{array}{l}\text { PCAO, } \\
\text { anterior } \\
\text { segment } \\
\text { ischemia }\end{array}$ & $\begin{array}{c}\text { Dilated pupil, exotropia, } \\
\text { ophthalmoplegia, hyphema, } \\
\text { hypopyon, cornea edema, } \\
\text { Ptosis }\end{array}$ & Immediately & One-step & $\begin{array}{c}\text { Topical and } \\
\text { systemic } \\
\text { abx }\end{array}$ & $\mathrm{HM}$ & 1.0 & $\begin{array}{l}\text { Resolved anterior } \\
\text { segment } \\
\text { inflammation }\end{array}$ & $3 \mathrm{M}$ \\
\hline $\begin{array}{l}\operatorname{Kim} Y J \\
2013[9]\end{array}$ & 30 & M & Bilateral & glabella & $\begin{array}{l}\text { Ophthalmic } \\
\text { artery } \\
\text { occlusion }\end{array}$ & $\begin{array}{l}\text { Dilated pupil, total } \\
\text { ophthalmoplegia, ptosis }\end{array}$ & NA & NA & NA & NLP & NLP & NA & NA \\
\hline $\begin{array}{l}\text { Current } \\
\text { study }\end{array}$ & 33 & $\mathrm{~F}$ & Bilateral & glabella & $\begin{array}{l}\text { Retinal } \\
\text { artery } \\
\text { occlusion }\end{array}$ & $\begin{array}{l}\text { Dilated pupil, RAPD, } \\
\text { conjunctival injection }\end{array}$ & Immediately & Five-step & $\begin{array}{l}\text { Carbogen, } \\
\text { HBOT, }\end{array}$ & $\begin{array}{l}\text { OD : } 20 / 20 \\
\text { OS : HM }\end{array}$ & $\begin{array}{c}\text { OD : } 20 / 20 \\
\text { OS }: 0.1\end{array}$ & $\begin{array}{c}\text { Recovery of } \\
\text { choroidal and retinal } \\
\text { circulation in the left } \\
\text { eye }\end{array}$ & $3 \mathrm{M}$ \\
\hline
\end{tabular}

$\mathrm{abx}=$ antibiotics; $\mathrm{BCVA}=$ best corrected visual acuity; $\mathrm{EAGLE}=$ European Assessment Group for Lysis in the EYE study; $\mathrm{F}=$ female; $\mathrm{HBOT}=$ hyperbaric oxygen therapy; $\mathrm{HM}=$ hand motion; $\mathrm{M}=$ male; $\mathrm{NA}=$ not available; NLP = negative light perception; PCAO = posterior ciliary artery occlusion; RAPD = relative afferent pupillary defect; $y r=$ years. 
Another issue that needs to be mentioned is the possibility of central nervous system infarction. Just as the injected materials can be pushed into the ophthalmic artery, an excessive force may also cause retrograde emboli into the internal carotid artery, resulting in a cerebrovascular event. In our review, 7 of the 46 cases $(7 / 46$, $15.2 \%)[4,10,15,17,30,36]$ had complications with a stroke event. Of these, 6 cases were following fat transfer, $[4,15,17,30,36]$ and the remaining case had hyaluronic acid injection [10]. Therefore, we should pay attention to each patient's neurological symptoms and signs. It is recommended that routine neuroimaging examination, such as CT or MRI, should be arranged in iatrogenic RAO to rule out the possibility of brain infarction.

\section{Conclusion}

In conclusion, considering there are no reported reliable treatments for iatrogenic RAO, a poor visual acuity outcome is inevitable. In this report, we offer our experience with HBOT for the treatment of iatrogenic RAO. We found that early HBOT had some beneficial effects on retinal perfusion and visual acuity, while there were no major complications. Therefore, along with recommended treatments by the EAGLE study, [5] HBOT seems worthwhile for iatrogenic RAO within the initial 24 hours if the equipment and a trained technician are available.

\section{Consent}

Written informed consent was obtained from the patient for publication of this Case Report and any accompanying images. A copy of the written consent is available for review by the Editor of this journal.

\section{Abbreviations \\ RAO: Retinal artery occlusion; FAG: Fluorescein angiography; OCT: Optical coherence tomography; MRI: Magnetic resonance imaging; HBOT: Hyperbaric oxygen therapy; BCVA: Best corrected visual acuity; CaHA: Calcium hydroxylapatite; EAGLE: European assessment group for lysis in the Eye.}

\section{Competing interests}

The authors declare that they have no competing interests.

\section{Authors' contributions}

YHH was involved in the design and execution of the study. Collection and management of the data were completed by SFH and SHT. YHH and SFH participated in the management and interpretation of the data. $\mathrm{YHH}$ and SFH participated in preparation, review, and approval of the manuscript. Both authors read and approved the final manuscript.

\section{Acknowledgements}

This work was sponsored partly by the National Cheng Kung University Hospital Research Fund (NCKUH-10305021). The funder had no role in study design, data collection and analysis, decision to publish, or preparation of the manuscript.

Received: 5 April 2014 Accepted: 8 October 2014

Published: 11 October 2014

\section{References}

1. Finn JC, Cox S: Fillers in the periorbital complex. Facial Plast Surg Clin North Am 2007, 15(1):123-132. viii.
2. Sung MS, Kim HG, Woo KI, Kim YD: Ocular ischemia and ischemic oculomotor nerve palsy after vascular embolization of injectable calcium hydroxylapatite filler. Ophthal Plast Reconstr Surg 2010, 26(4):289-291.

3. Peter S, Mennel S: Retinal branch artery occlusion following injection of hyaluronic acid (Restylane). Clin Experiment Ophthalmol 2006, 34(4):363-364.

4. Park SW, Woo SJ, Park KH, Huh JW, Jung C, Kwon OK: latrogenic retinal artery occlusion caused by cosmetic facial filler injections. Am J Ophthalmol 2012, 154(4):653-662. e651.

5. Schumacher M, Schmidt D, Jurklies B, Gall C, Wanke I, Schmoor C, Maier-Lenz H, Solymosi L, Brueckmann H, Neubauer AS, Wolf A, Feltgen NE, AGLE-Study Group: Central retinal artery occlusion: local intra-arterial fibrinolysis versus conservative treatment, a multicenter randomized trial. Ophthalmology 2010, 117(7):1367-1375. e1361.

6. Lazzeri D, Agostini T, Figus M, Nardi M, Pantaloni M, Lazzeri S: Blindness following cosmetic injections of the face. Plast Reconstr Surg 2012, 129(4):995-1012.

7. Egbert JE, Paul S, Engel WK, Summers CG: High injection pressure during intralesional injection of corticosteroids into capillary hemangiomas. Arch Ophthalmol 2001, 119(5):677-683.

8. Roberts SA, Arthurs BP: Severe visual loss and orbital infarction following periorbital aesthetic poly-(L)-lactic acid (PLLA) injection. Ophthal Plast Reconstr Surg 2012, 28(3):e68-e70.

9. Kim YJ, Choi KS: Bilateral blindness after filler injection. Plast Reconstr Surg 2013, 131(2):298e-299e.

10. He MS, Sheu MM, Huang ZL, Tsai CH, Tsai RK: Sudden bilateral vision loss and brain infarction following cosmetic hyaluronic Acid injection. JAMA Ophthalmol 2013, 131(9):1234-1235.

11. Kim YJ, Kim SS, Song WK, Lee SY, Yoon JS: Ocular ischemia with hypotony after injection of hyaluronic acid gel. Ophthal Plast Reconstr Surg 2011, 27(6):e152-e155.

12. Allali J, Bernard A, Assaraf E, Bourges JL, Renard G: [Multiple embolizations of the branches of the ophthalmic artery: an unknown serious complication of facial surgeries]. J Fr Ophtalmol 2006, 29(1):51-57.

13. Castillo GD: Management of blindness in the practice of cosmetic surgery. Otolaryngol Head Neck Surg 1989, 100(6):559-562.

14. Coleman SR: Avoidance of arterial occlusion from injection of soft tissue fillers. Aesthet Surg J 2002, 22(6):555-557.

15. Danesh-Meyer HV, Savino PJ, Sergott RC: Case reports and small case series: ocular and cerebral ischemia following facial injection of autologous fat. Arch Ophthalmol 2001, 119(5):777-778.

16. Dreizen NG, Framm L: Sudden unilateral visual loss after autologous fat injection into the glabellar area. Am J Ophthalmol 1989, 107(1):85-87.

17. Egido JA, Arroyo R, Marcos A, Jimenez-Alfaro I: Middle cerebral artery embolism and unilateral visual loss after autologous fat injection into the glabellar area. Stroke 1993, 24(4):615-616.

18. Feinendegen DL, Baumgartner RW, Vuadens P, Schroth G, Mattle HP, Regli F, Tschopp H: Autologous fat injection for soft tissue augmentation in the face: a safe procedure? Aesthet Plast Surg 1998, 22(3):163-167.

19. Kwon DY, Park MH, Koh SB, Dhong ES, Baek SH, Ryu HJ, Park K: Multiple arterial embolism after illicit intranasal injection of collagenous material. Dermatol Surg 2010, 36(7):1196-1199.

20. Lee DH, Yang HN, Kim JC, Shyn KH: Sudden unilateral visual loss and brain infarction after autologous fat injection into nasolabial groove. Br J Ophthalmol 1996, 80(11):1026-1027.

21. Lee YJ, Kim HJ, Choi KD, Choi HY: MRI restricted diffusion in optic nerve infarction after autologous fat transplantation. J Neuroophthalmol 2010, 30(3):216-218.

22. Mori K, Ohta K, Nagano S, Toshinori M, Yago T, Ichinose Y: [A case of ophthalmic artery obstruction following autologous fat injection in the glabellar area]. Nippon Ganka Gakkai Zasshi 2007, 111(1):22-25.

23. Park SH, Sun HJ, Choi KS: Sudden unilateral visual loss after autologous fat injection into the nasolabial fold. Clin Ophthalmol 2008, 2(3):679-683.

24. Park SJ, Woo SJ, Park KH, Hwang JM, Hwang GJ, Jung C, Kwon OK: Partial recovery after intraarterial pharmacomechanical thrombolysis in ophthalmic artery occlusion following nasal autologous fat injection. J Vasc Interv Radiol 2011, 22(2):251-254.

25. Selmanowitz VJ, Orentreich N: Cutaneous corticosteroid injection and amaurosis. Analysis for cause and prevention. Arch Dermatol 1974 110(5):729-734.

26. Shin H, Lemke BN, Stevens TS, Lim MJ: Posterior ciliary-artery occlusion after subcutaneous silicone-oil injection. Ann Ophthalmol 1988, 20(9):342-344. 
27. Tangsirichaipong A: Blindness after facial contour augmentation with injectable silicone. J Med Assoc Thai 2009, 92(Suppl 3):S85-S87.

28. Teimourian B: Blindness following fat injections. Plast Reconstr Surg 1988, 82(2):361.

29. von B: Multiple embolisms in the fundus of an eye after an injection in the scalp. Acta Ophthalmol (Copenh) 1963, 41:85-91.

30. Yoon SS, Chang DI, Chung KC: Acute fatal stroke immediately following autologous fat injection into the face. Neurology 2003, 61(8):1151-1152.

31. Menzel-Severing J, Siekmann U, Weinberger A, Roessler G, Walter $P$, Mazinani B: Early hyperbaric oxygen treatment for nonarteritic central retinal artery obstruction. Am J Ophthalmol 2012, 153(3):454-459. e452.

32. Beiran I, Goldenberg I, Adir Y, Tamir A, Shupak A, Miller B: Early hyperbaric oxygen therapy for retinal artery occlusion. Eur J Ophthalmol 2001, 11(4):345-350

33. Weinberger AW, Siekmann UP, Wolf S, Rossaint R, Kirchhof B, Schrage NF: Treatment of Acute Central Retinal Artery Occlusion (CRAO) by Hyperbaric Oxygenation Therapy (HBO)-Pilot study with 21 patients. Klin Monatsbl Augenheilkd 2002, 219(10):728-734.

34. Oguz H, Sobaci G: The use of hyperbaric oxygen therapy in ophthalmology. Surv Ophthalmol 2008, 53(2):112-120.

35. Edwards ML: Hyperbaric oxygen therapy. Part 1: history and principles. J Vet Emerg Crit Care 2010, 20(3):284-288.

36. Bernardi C, Favetta U, Pescatori M: Autologous fat injection for treatment of fecal incontinence: manometric and echographic assessment. Plast Reconstr Surg 1998, 102(5):1626-1628.

\section{Submit your next manuscript to BioMed Central and take full advantage of:}

- Convenient online submission

- Thorough peer review

- No space constraints or color figure charges

- Immediate publication on acceptance

- Inclusion in PubMed, CAS, Scopus and Google Scholar

- Research which is freely available for redistribution 